\title{
A Design for Graduate Students of Ceit Department Using Community of Practice Framework
}

\author{
Hamza Polat ${ }^{1 *}$, Ömer Delialioğlu ${ }^{1}$
}

${ }^{1}$ Middle East Technical University (METU), Ankara 06000, TURKEY

*Corresponding Author: phamza@metu.edu.tr

Citation: Polat, H., \& Delialioğlu, Ö. (2019). A Design for Graduate Students of Ceit Department Using Community of Practice Framework. Mediterranean Journal of Social \& Behavioral Research, 3(3), 43-46. https://doi.org/10.30935/mjosbr/9593

\begin{abstract}
Many of the faculty members in Turkey dedicate their working time on teaching, doing research, and counseling graduate students. Although teaching activities appear to be the main workload, conducting research seems to be the most important factor for academic promotions. Therefore, knowledge, skills and experience of faculty has a strong effect on higher education. On the other hand, most of the freshmen-graduate students in academic world don't have experience design, run and report scientific research by making use of the existing literature, research design and methods.

This study focuses on the possibility for new learning environments where graduate students doing their Master of Science or Doctoral degrees could work as efficient as an experienced researcher. The graduate students in the Department of Instructional Technology at a public university in Ankara were observed to figure out the research requirements of young researchers. Community of Practice Theory $(\mathrm{CoP})$ was used as a theoretical framework in doing a course design the requirement addressed in the analysis results. As a result, a new design based on the CoP was proposed, so as to increase the productivity in academic studies.
\end{abstract}

Keywords: research agents, research groups, community of practice

Received: 15 Jul. 2019 • Revised: 22 Oct. 2019 • Accepted: 15 Nov. 2019

\section{INTRODUCTION}

The main purpose of this study is to provide a community of practice design for doctoral candidates to improve their research skills in academia. Academic staffs mainly concern with their undergraduate students' education. They attempt to provide a better learning setting in which students could be able to improve their skills. That forces them to focus on teaching activities and disregard their academic progress in universities. However, teaching activities are not the only way of academic promotion. Besides such kind of activities, it is a requirement for an academic staffs to be capable of conducting research own their own. That requires adequate knowledge, certain skills and prior experience to manage the process in an efficient and effective way.

Graduate students begin their career with an enthusiasm. However, this process is long and requires self-regulation and motivation. In addition, they need certain skills to struggle with the challenges of academic research. In this regard, participation in a research group would be a possible solution for them to get used to research environment. Such kind of groups can be arranged around collaborative learning (Jonson, Jonson \& Smith, 1991) and community of practice (CoP) (Wenger, 1999; Wenger, McDermott \& Snyder, 2002) theoretical orientations. A community takes its root from the sociological term "gemeinschaft" (Tönnies, 2001) therefore community of practice is a learning environment in which a group of people interacts on a certain task by sharing a common sense (Wenger, McDermott \& Snyder, 2002).

In literature there are many successful implementations of CoP designs (Guerin, Xafis, Doda \& Gillam, 2013; Li \& Vandermensbrugghe, 2011; Salas-lopez, Deitrick, Mahady, Moser, Gertner \& Sabino, 2011) addressing the different disciplines. Although the common point in such studies is about the organizing writing or research group to increase members' skills, different types of interests could be arranged around the CoP. Guerin at all. (2013), for example, set up a writing group consisting of $\mathrm{PhD}$ students who are from different countries and disciplines in a public healthy school. At the end of the project, they observed positive improvements on what behaviour members had deficiency at the beginning. Li \& Vandermensbrugghe (2011), in one another study, provided support to the ongoing thesis of international doctoral students in scope of a community. To overcome the problems they faced, members were actively involved in: reading draft pages, commenting language issues, identifying unclear parts, suggesting alternative improvements, revising work-in-progress, and lastly supporting each other socially. Additionally, Salas-lopez at all. (2011), conducted a study based on a writing community developed by the colleagues from a hospital sharing same passion to take part in a publication process of academic writing. The study reports the success 


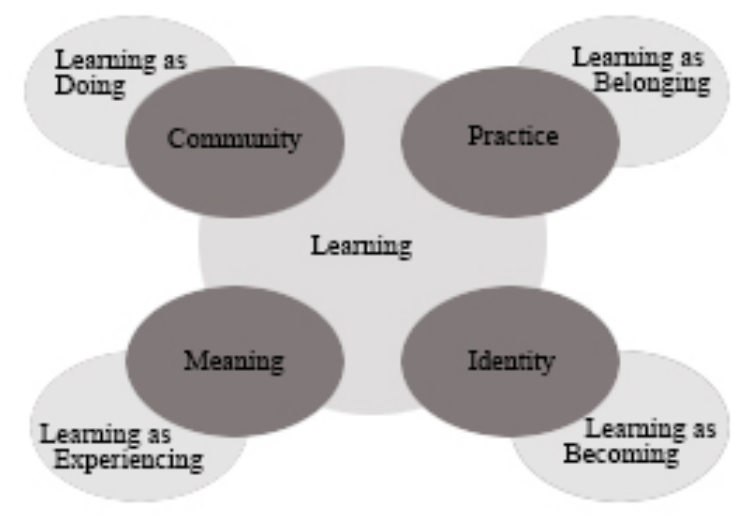

Figure 1. Components of social theory of learning: an initial inventory (Wenger, 1998, p.5).

of community since all members take care the requirements of their task and join group meetings regularly. All these studies, although, are good implementation of $\mathrm{CoP}$, they did not provide a structural framework for the ones in academia. Furthermore, effectiveness of such kind of designs could different depending on the contextual, cultural issues. Therefore, in this study it is aimed to propose a CoP framework by which graduate students could be able to increase their research skills at the Department of Computer Education and Instructional Technology in Middle East Technical University (METU), Turkey.

\section{CONTEXT}

Community of practice includes the basic social learning structures (Wenger, 1999). The following figure illustrates the main four aspects of social learning. In the light of these four dimensions, requirement for a CoP design in the department of Computer Education and Instructional Technology (CEIT) at METU was summarized in Figure 1.

Wenger (1999) describes learning as an interaction between "social competence" and "personal experience." Let's consider two concepts in CEIT condition. Nearly each session newcomers participate the department. Probably most of them feel, as being inadequate in field since they will face many issues will be learned. The social environment around the newcomers shaped the members' competence. However, due to the cultural differences and personal characteristics of newcomers, they might perceive themselves out of the community. Normally, "competence pulls our experience", yet if the newcomers do not feel themselves as a core member of department, then it would be difficult to reach expected situation in terms of experience. Therefore, the first task we need to accomplish is that all the graduate students in department should feel themselves as valuable as the core members.

Community is a kind of "social configurations in which our enterprises are defined as worth pursuing and our participation is recognizable as competence" (Wenger, 1999). Thus, community consists of members participating learning activities and concerning about each other's. In this sense CEIT department could be described as a community including 11 faculty members: three of professor, an associate professor, three of assistance professor and the rest of instructor with $\mathrm{PhD}$; and 37 research assistants, who are already master or $\mathrm{PhD}$ students, conducting their research under the control of their advisors; and many other undergraduate, graduate and $\mathrm{PhD}$ students. Except from instructors, other faculty members are working with at least a $\mathrm{PhD}$ candidate. Generally, faculty members construct own research groups and it would be very difficult to be part of these research groups under a certain advisor for the graduate students due to the limitation of faculty members and lack of adequate faculties experienced in an expected field. Therefore there are many researchers in department carrying out their study in an uninterested topic. Moreover, although it is not clear which faculty interests to what topic, and graduate students sometimes have not opinion about their close roommates ongoing research. In other words, there is a gap regarding what graduate students are doing in department. As a result, to put the researchers together and to overcome the challenges about lack of expected faculty, it is a requirement to develop a community of practice design for CEIT at METU.

Being a member of community requires developing an identity about the community of practice. Individuals should feel themselves as part of the group in terms of learning style and so on. In our case, it would be beneficial to reduce the time of developing identity to increase productivity of members. However, since most of the students enrolling CEIT are coming from different cultures and even different educational backgrounds due to the different programs, reducing the orientation period would be difficult. Therefore, developing new communities including several members in department could be useful to reach an expected identity. Any member could learn many issues regarding department or university by interacting each other.

One other aspect of social learning and thereby community of practice is "practice". Practice requires "mutual engagement in action" (Wenger, 1999). Having considered the department, few researchers participate a mutual studies There are, of course, some groups conducting a research collaboratively. But, majority is out of the circle. We can say that there are few research groups comprised by naturally or authority, very few groups sharing some common senses, and many individual independent from each other. Majority of independent individuals are struggling lack of experience about research in field sine mainly they are newcomers. To make these researchers experienced, it would be helpful to comprise them into a research group. By means of these groups, newcomers could learn how to conduct a research, how to write a dissertation, proposal, and even how to publish a paper. However, the current condition of department is not capable of providing such opportunities.

"Practice" is the first and foremost part of social learning, by means of "practice" individuals' engagement increase toward to learning activities meaningfully (Wenger, 1998). Wenger (1999), describe the "meaning" aspect of learning as " an ability to experience our life and the world as meaningful" (Wenger, 1998). It can be noted that "meaning" component would be interrelated to the personal characteristics of community members. Thus, being an experienced researcher requires being part of many researches. By individually, it would be difficult to make meaning the world effectively since it might restrict individuals' point of view. One way of overcoming this problem is to benefit some other's experiences. Going back to the departments needs, everybody in department will need one other person who would be able to contribute his/her engagement and experience. 


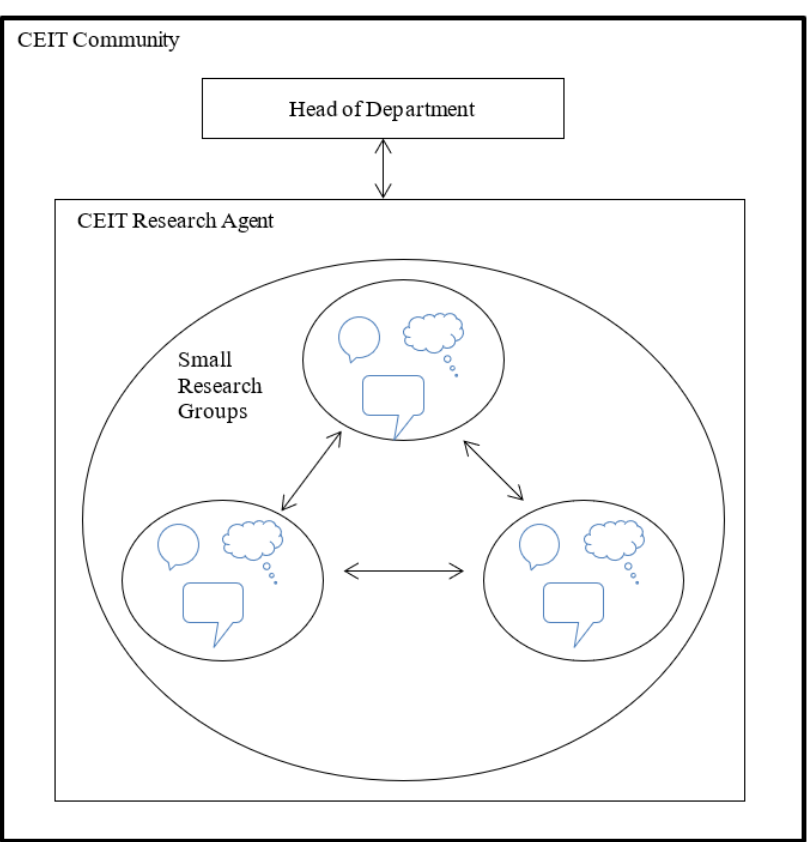

Figure 2. Dynamics of CEIT Agent

\section{DESIGNING A CoP FOR CEIT}

Designing a CoP framework requires "inquiry", "design", "prototype", "lauch" and "grow" processes (Cambridge, Kaplan, \& Suter, 2005). This study focuses on the "design stage" which defines the activities, technologies, group processes, and roles of members in CoP. It is provided several CoP dynamics for CEIT including administration, research agent, and members. As illustrated Figure 2, there are three component of design: head of department, CEIT research agent, and small research groups.

Head of Department: Every organization has a manager dealing with the authority issues. In this case, chief of department's role is to manage organization of Research Agent's activities. That is, instead of being an active member in community, the foremost responsibility of manager is to provide opportunities to CEIT Research Agent and contribute to the agents' activities.

CEIT Research Agent: The main workload about planning, designing, developing and implementation of community of practice occur in this unit. The main role of this agency is to manage the research activities. At the beginning of each session, this unit organizes a seminar to which the volunteered researchers attend. For this seminar, an announcement is made on the web site of department and faculty toward disciplinary and interdisciplinary fields since it is aimed to comprise the volunteer researchers under a community. Most of the decision regarding identifying members of small groups, research topics, arranging meeting times and schedule are clarified at first seminar. To observe the small research groups' progress, this comity organize meetings every moth. Before coming to presentation, each group sends their ongoing study in an appropriate format to other members of unit. All the members have to read such studies before coming to meeting. During these meetings small groups presents their study to the rest member of Agent. These groups take constructive feedbacks by means of such presentations, then with the light of those feedbacks they conduct their

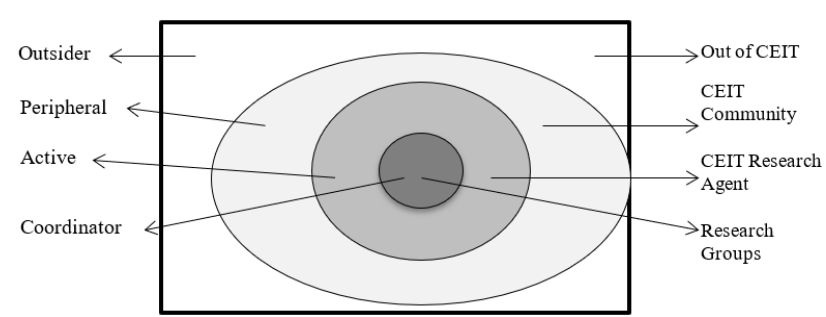

Figure 3. Degrees of CEIT research agent community participation

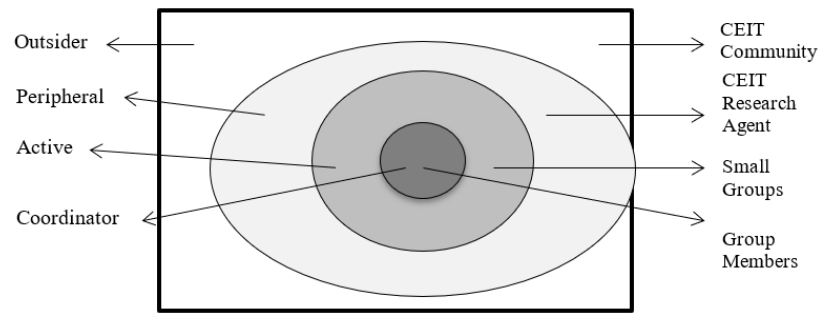

Figure 4. Figure on top of a page

study till the second monthly meeting. This enables small groups to interact each other, so that they benefit the experiences of other groups.

CEIT research agency also communicates the outside of community of practice. To do so, a web site is created about the group and organizational activities. Not only small groups but also the external world follow the unit and group activities on this website. This makes groups to increase their motivation and to develop an identity. Further, it would be sometimes beneficial to invite guest researchers out of the community to the monthly meetings so that the groups gain a different perspective.

Consequences of an observed behavior are important issues while learning something new. Bandura (1986), thus, emphasizes the role of social reinforcement in learning setting. In this sense, it was planned to provide an award to the successful research groups by the research agency. Research unit identifies standards influencing take of award. The most essential factor is that researchers should publish ongoing study on a SCI or SSCI journal. By this way it is aimed to motivate the other groups as well.

Small Research Groups: These groups consist of certain members within the range of five to eight individuals, which are the core structure of CEIT Research Agent. The Agent identifies members of small groups at first session's seminar. While doing that the most important principle is to make such groups heterogenic. In other words, cultural, disciplinary and experience diversity are the main factors influencing structure of each groups (Guerin, at all, 2013; Salas-lopez, at all, 2011). In contrast to CEIT research agency, small research groups organize weekly meetings. At the first meeting an agreement is concluded among group members. This agreement includes group rules about meeting times, task sharing, and even penalties. Attendance is requirement for the members of such groups. In case of emergency, members notify the rest of group members in advance. During these meetings, group members discuss their ongoing study, and give feedback each other. To make differences on research new roles are identified for the next week's meeting.

Both Figure 3 and Figure 4 illustrate the participation community of practice. It can be understand from the figures that there are two types of community in this design. Each type possesses its dynamics with the members' roles, which are explained previously. As a result we 
can state that three are two types of CoP integrated each other. We believe that providing opportunity for experienced and nonexperienced researchers in conducting research as being a community increase the efficiency of academic culture.

\section{DISCUSSION}

The motivating factor for CEIT Research agent is that academic staffs are already aware of the promoted effect of academic research. In this regard the agency provides two type of facilitates for graduate students: collecting researchers around a common sense and combining educational and cultural dimensions of members into one dimension. Firstly, all members are gathering around a common sense. For example, preparing a conference paper could be an attractive point for graduate students to attend the community. According to our observation and informal interview results the starting point of agency is addressing nearly all-graduate students in department. From the beginning of the first meeting up to the next small group meetings, being a product-oriented community will be the most motivated issue, affecting members.

Secondly, in general there are certain individuals having different educational and cultural backgrounds in the universities around the world, so does in our department as well. Some of them, although, are capable of conducting research by themselves, they are not so much effective as expected level due to the cultural diversity. Additionally, the ones graduated from different universities, most of the time straggling with lack of experience regarding research or second language proficiency. Therefore, the design is also appealing to combine such kind of cultural and educational diversities.

The main structure of design is consisting of two dynamics: small groups and general structure including all participants even project managers. The role of CEIT Research Agency is to manage the process of research activities in department on behalf of department chief. On the other hand, small groups works autonomously and are the core of design. Small groups arrange their schedule by themselves, by this way the flexibility of relationship among group members will increase. In order to prevent the small groups as acting freely from the general structure, at the kick off meeting of agent a general agreement among members, small groups and the agent should be made. All the possible challenges like time management should be verbalized in these meetings in advance. To increase the identities of participants as a member of a research community, it is crucial to organize some other meetings addressing to all members. By means of such meeting they should present their current status and they should get some feedbacks about their study. Because, the first meeting is although making members more motivated than the small group meetings, many other general meetings should be organized monthly. There should be some dynamics within the community that can be able to control the workload issue of members. Because it is a requirement to accomplish the assigned tasks for the members in advance, there could be some solutions in case of emergency situations like workload.
Overall, we believe that the idea behind CEIT research agent is exiting for CEIT researchers. Especially, it is product oriented and this makes them motivated to do something. In this sense, we recommend some suggestions to increase effectiveness and sustainability of such a community. Followings are some suggestions:

- Such a community should be established at the beginning of semester. By this way members can find time to deal with their study in wide time interval.

- Communication between agent members should be increased. This could be for both general and small groups. To do so, many online tools should be provided to make announcements in community.

- A faculty staff should follow agent's activities by participating community actively to increase sustainability and seriousness of community.

Role lists should be provided in advance for both agent administration and small groups. Group leaders should be responsible for applying such rules.

\section{REFERENCES}

Bandura, A. (1986). Social foundations of thought and action: A social cognitive theory. Englewood Cliffs, NJ: Prentice Hall.

Cambridge, D., Kaplan, S., \& Suter, V. (2005). Community of Practice Design Guide: A Step-by-Step Guide for Designing \& Cultivating Communities of Practice in Higher Education.

Ferdinand Tönnies (ed. Jose Harris) (2001). Community and Civil Society. Cambridge University Press.

Guerin, C., Xafis, V., Doda, D. V., Gillam, M. H., Larg, A. J., Luckner, H., Jahan, N., Widayati, A., \& Xu, C. (2013). Diversity in collaborative research communities: a multicultural, multidisciplinary thesis writing group in public health. Studies in Continuing Education, 35(1), 37-41. https://doi.org/10.1080/ 0158037X.2012.684375

Li, L. Y., \& Vandermensbrugghe, J. (2011). Supporting the thesis writing process of international research students through an ongoing writing group. Innovations in Educational and Teaching International, 48(2), 195-205. https://doi.org/10.1080/14703297 .2011 .564014

Salas-Lopez, D., Deitrick, L., Mahady, E. T., Moser, K., Gertner, E. J., \& Sabino, J. N. (2012). Getting Published in an AcademicCommunity Hospital: The Success of Writing Groups. Journal of General Internal Medicine, 27, 113-116. https://doi.org/10.1007/ s11606-011-1872-9

Wenger, E., McDermott, R. A., \& Snyder, W. (2002). Cultivating communities of practice: A guide to managing knowledge. Harvard Business Press.

Wenger, E. (1998).Communities of practice: Learning, meaning, and identity.Cambridge University Press.https://doi.org/10.1017/ CBO9780511803932 